\title{
Weight Reduction of Automobile Using Glass-Mat Thermoplastic Composites in Spare-Wheel Well
}

\author{
Çiğdem Bilge* ${ }^{*}$, Tamer Aydıner $\left(\mathbb{D}\right.$, Çağrı Akdeniz ${ }^{\oplus}$, Ahmet Mert Soyer $(\mathbb{0}$, Levent Aksel \\ TOFAŞ Türk Otomobil Fabrikası R\&D Center, Bursa-TURKEY
}

\begin{abstract}
The reduction of carbon dioxide emission and light weighting are the most important issues in automotive industry. Lightweight, high strength, high corrosion resistance and easy manufacturing of composite materials have been used in automotive sector in recent years.

Glass-mat thermoplastic (GMT) materials are based on polypropylene and it stands out among the composite materials used in the automotive industry with existing long fiber and / or endless glass matt structure as reinforcing material providing high strength, performance impact, energy absorption and recyclability. The material used in this study utilizes GMTex reinforced composite structure with multi-layer glass fiber technology that is reinforced with woven and randomly laid fiber structures to enhance the superior properties of GMT. The spare-wheel well (SWW) which includes many parts weighs about $10 \mathrm{~kg}$ and it is a potential area for weight reduction. This study has been based on the boundary conditions of the existing sheet material in this area, the current performance has been maintained with the GMT/GMTex material to provide approximately $2 \mathrm{~kg}$ weight reduction. The effects of orientations of GMTex reinforcement on crash performance have been verified by the rear impact virtual analyzes. Besides, the joining methods and some design criticalities during the integration of composite SWW part in BIW (Body in White) have been mentioned.
\end{abstract}

Keywords: GMT, GMTex, Spare-Wheel Well, Thermoplastics

\section{INTRODUCTION}

The weight of a vehicle is the predominany factor in terms of the reduction of emission and fuel consumption [1]. As can be seen in Fig 1, around $75 \%$ of the weight of a motor vehicle is divided between body, powertrain, suspension and chassis components. Reducing the weight of the body-in -white means smaller engines can be employed and smaller suspension systems are needed, so reducing the total weight of the body is crucial towards achieving lighter vehicles [2].

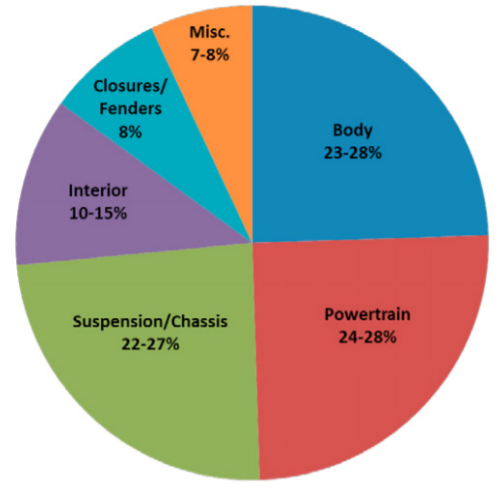

Figure 1. Breakdown of mass of passenger vehicle by components (approximate). [6]
Considering the lightweight and high energy capacity of the automotive industry, composite material usage is increasing day by day with their high specific strength and stiffness and high energy absorption capacity. [1]

The development of automobile technologies necessitates the use of lighter materials in automobile bodies.

Different researchers have implemented different types of composite materials such as carbon fiber reinforced plastic (CFRP), glass fiber reinforced plastic (GFRP), sheet moulding compound (SMC), and glass mat thermoplastic (GMT) for bumper beam to improve the bumper subsystem performance as it can offer lightweight as well as reduce the energy consumption, [3-5]. Currently, SMC and GMT are widely used because of easy formability, low material and manufacturing costs, even though CFRP and GFRP Different researchers have implemented different types of composite materials such as carbon fiber reinforced plastic (CFRP), glass fiber reinforced plastic (GFRP), sheet moulding compound (SMC), and glass mat thermoplastic (GMT) for bumper beam to improve the bumper subsystem performance as it can offer lightweight as well as reduce 
the energy consumption, [3-5]. Currently, SMC and GMT are widely used because of easy formability, low material and manufacturing costs, even though CFRP and GFRP Different researchers have implemented different types of composite materials such as carbon fiber reinforced plastic (CFRP), glass fiber reinforced plastic (GFRP), sheet moulding compound (SMC), and glass mat thermoplastic (GMT) for spare wheel well to improve the performance as it can offer lightweight as well as reduce the energy consumption, [3-5]. Currently, SMC and GMT are widely used because of easy formability, low material and manufacturing costs, even though CFRP and GFRP can offer better mechanical performances. GMT is more appreciated in automotive industries because of its short shaping and curing cycles. Moreover, GMT is a recyclable material because of its thermoplastic matrix.

Nowadays in the European Union (EU), about $75 \%$ of endof-life vehicles, are recyclable, i.e. their metallic part. The rest ( $\sim 25 \%)$ of the vehicle is considered to be waste and generally goes to landfills, [6]. EU legislation requires the reduction of this waste to a maximum of $5 \%$ by 2015 . To take into account this directive, in this paper a recyclable GMT material has been chosen as a potential candidate for the spare whell well (that is a close section thin-walled beam) construction and its performance is compared with reference material, steel, and CFRP non-recyclable composite material solutions.

GMT material stands out as a material with high mechanical strength, high energy absorption capacity and recyclability [2] Furthermore, GMT material provides good resistance to chemicals and moisture at low temperatures [3]. The weights of automotive structural parts can be reduced using these benefits without sacrificing their mechanical performance. [4]

The SWW is a common component on most passenger vehicles with a trunk or rear hatch (back door). This round or square pan is mounted into the trunk opening, where it holds an extra wheel, tire iron, and jack. [5] (Fig. 1). Moreover, it provides a big advantage for the structure and crash safety of vehicle. That is to say it's an accomplished applicant for composite-metal conversion. [6]
This paper represents, a weight reduction study using GlassMat Thermoplastic Composites (GMT) in Spare-Wheel Well (SWW) on the car body to reduce the weight of the vehicle without sacrificing their mechanical performance.

The GMT materials manufactured by Mitsubishi Chemical Advanced Materials Composites are based on polypropylene (PP) and polyamide (PA). Reinforcement is provided by long fibers and/or endless glass mat technology. And this is the key to GMT's success. For unreinforced and short-fiber-reinforced thermoplastics become brittle at low temperatures and shatter dangerously in crashes. Its special long fiber technology ensures high energy absorption before fracture and thereafter benign failure behavior without sharp lines of fracture.

Based on GMT, the composite GMTex has been further developed for applications demanding high impact resistance, strength and durability. In the production of these high-performance thermoplastic composites, the basic materials of polypropylene (PP), polyamide (PA) and thermoplastic polyester (TPP) are reinforced with woven and randomly laid fibers (multi-layer glass fiber technology).

GMTs are an established material class that are used to produce complex components, principally for the automotive industry. [7]

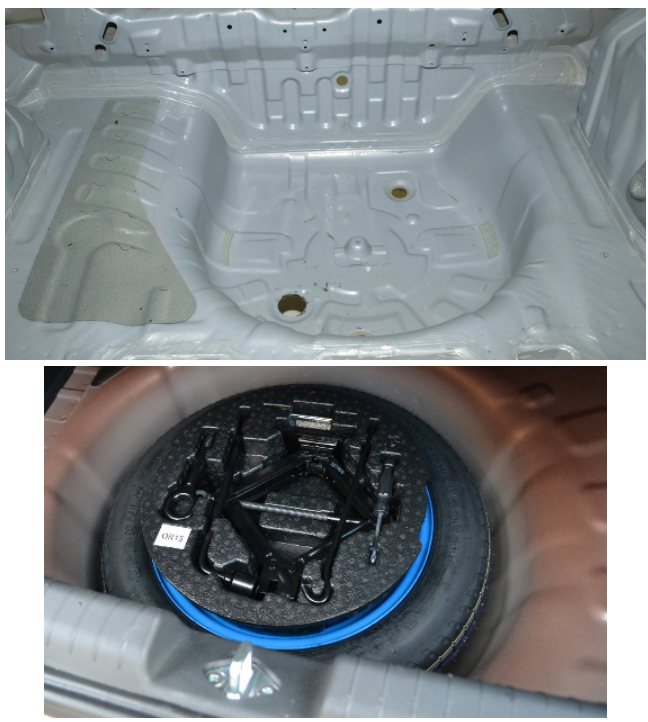

Figure 1. Steel Spare Wheel well in BIW and with extra wheel [8]

Table 1. Mechanical Properties of GMT/ GMTex Materials [14]

Material Properties

\begin{tabular}{lcccc}
\hline Material & $\begin{array}{c}\text { Density } \\
(\mathrm{g} / \mathrm{cm} 3)\end{array}$ & $\begin{array}{c}\text { E-Module } \\
(\mathrm{MPa})\end{array}$ & $\begin{array}{c}\text { Tensile Strength } \\
(\mathrm{MPa})\end{array}$ & $\begin{array}{c}\text { Specific Energy } \\
\text { absorption } \\
(\mathrm{kJ} / \mathrm{kg})\end{array}$ \\
\hline Steel & 7.85 & $210^{\prime} 000$ & $270-1^{\prime} 500$ & 10 \\
PP-GMT & $1.05-1.35$ & $3^{\prime} 500-8^{\prime} 300$ & $60-140$ & 30 \\
PP-GMTex & $1.22-1.50$ & $7^{\prime} 000-24^{\prime} 000$ & $200-450$ & 40
\end{tabular}


Compared to GMT, GMTex is specially developed for applications that require high impact resistance and high durability. Polypropylene (PP), polyamide (PA) and thermoplastic polypropylene (TPP) matrices are reinforced with randomly laid fibers (multilayer glass fiber technology) in the production of this high performance GMTex material. [3]

The GMTex material also has better impact damping when it is compared with GMT material. For this reason, in addition to having more benefit than GMT in terms of weight reduction, it is also possible to replace metal materials for structural parts. [7]. (Fig. 2). [9]

Results of side impact tests:

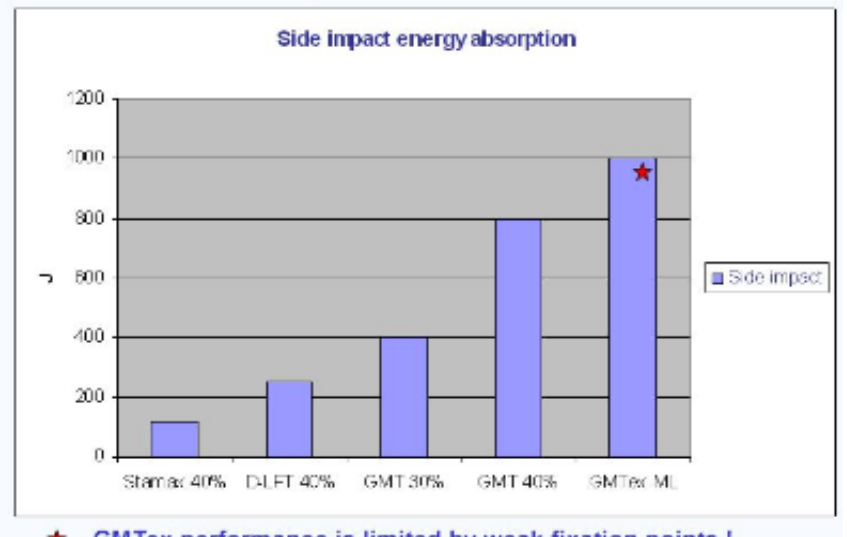

* GMTex performance is limited by weak fixation points !

Figure 2. Results of side impact test [9]

\section{DEVELOPMENT PROCEDURE}

Spare-Wheel Well (Fig 1) is a structural component on the underbody structure between rear rails and front of rear panel. This component should be able to absorb the energy which will be transferred during rear crash. Many other automotive makers provide light weighting through using different composite material instead of using steel for spare wheel well area. (Fig 3) [8]

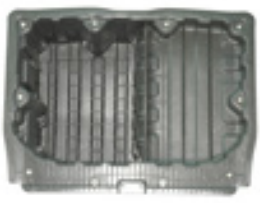

PP GF 30

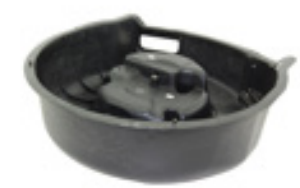

PP GM 40/PP GM 45

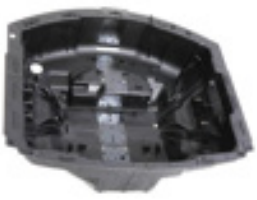

PA BKV 60

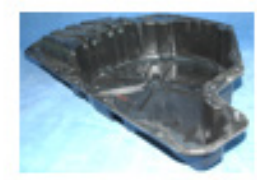

Up GF 29
Figure 3. Benchmarking of composite SWW [8]

GMT is an abbreviation for glass fiber thermoplastic material. GMT consists of thermoplastic matrix and glass fiber reinforcement. Which can be short or continuous. [2]

GMT has a short history and rapid development. It has good mechanical property and short shaping cycling.

It can form into large and complex parts with good dimen- sional Stability. (Fig 4) [9] Nevertheless, its extraordinary properties, weight reduction potential and the advantages that it provides during production are the significant reasons to prefer GMT instead of other composite materials.

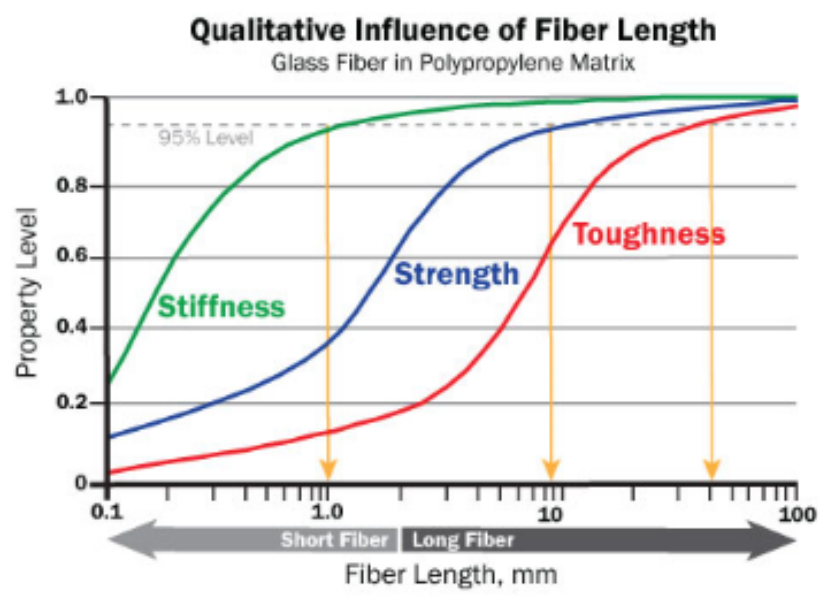

Figure 4. Qualitative Influence of Fiber Length [10]

Molded GMT part is almost isotropic with $50-300 \mathrm{~N} / \mathrm{mm}^{2}$ strength. GMT part has good resistance to impact and recuperability. Therefore, GMT is becoming widespread especially in European automobile industry to produce front end, seat frame, engine noise shield, bumper, instrument panel bracket and so on. [2]

Various metal brackets, plastic plugs and insulating materials on the steel part are integrated into the new composite design (Fig 5 ) This also gave us a cost advantage. The rear floor design of the vehicle is almost completely differentiated by the composite design.

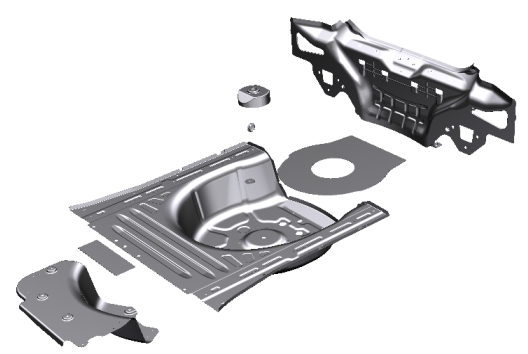

Figure 5. Steel design of Spare-Wheel Well

\section{VIRTUAL VERIFICATIONS}

\section{Load cases for spare Wheel Well}

SWW is located in rear side of the vehicle that assembled by using spot welding method, it carries a spare tire in it, over $23 \mathrm{~kg}$ weight. (Fig.6)

In this study final element model has been created at SWW zone for all surrounded components by using Altair-Hyper mesh software by adding of spare wheel \& repair kit weights. $\mathrm{NVH}$, safety \& structural virtual analyzes have been done in complete vehicle level and thereby target values have been defined for composite material. (Fig.5). Composite material that can replace steel material should provide first these target values and will lose weight without compromising of vehicle performance. 


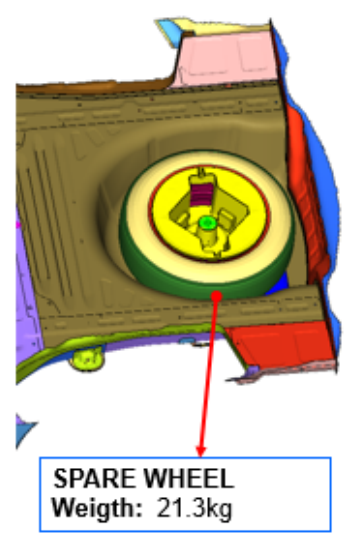

Figure 6. Part Production with GMTex

\section{Modal Analysis}

Modal analysis for NVH calculations is the basic analysis that determines the vehicle body performance in the product development process. This analysis is usually performed during each project period and body design changes, and the body $\mathrm{NVH}$ performance is constantly monitored.

Modal analysis is performed to calculate the natural frequencies of the vehicle. The results of the analysis are evaluated and the value are tried to be above the target value. When modal analysis of the vehicle was made, BIW (Body in White) model was used. (Fig 7)

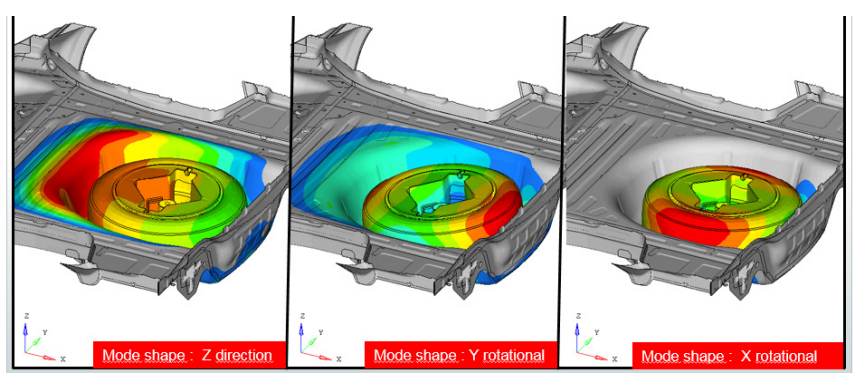

Figure 7. Targets of modal analysis

Natural frequency analysis of the relevant region has been carried out were found to provide target values. (Fig 8) ments. The wheel well must stay attached to the vehicle frame after a crash. [5]

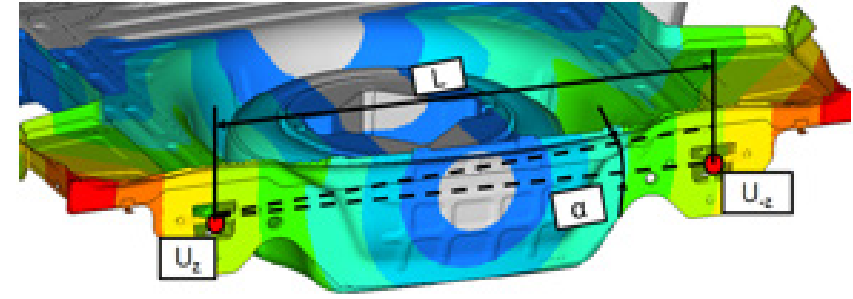

Figure 9. Torsional stiffness calculation

For the evaluation of the rear crash performance of the vehicle TRIAS 33 has been executed. TRIAS 33 basically controls the deformations on the fuel pipes and fuel tank. Within the TRIAS 33 a rigid barrier has been impacted with 52 $\mathrm{km} / \mathrm{h}$ to the vehicle from the rear side. [11] (Fig 10)

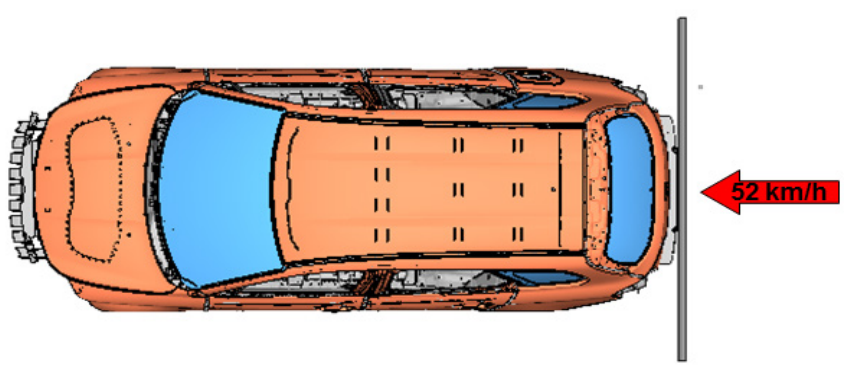

Figure 10. Rear impact condition of the vehicle for TRIAS 33 validation [11]

After the analyzes made, in the composite part; the effect of the GMTex amounts and positions used in GMTex, especially on the rear crash performance, has been observed.

\section{FIXING METHOD}

The biggest function of adhesives is to join the dissimilar materials with no direct contact between parts. It is possible to provide load transmission by providing a more suitable stress distribution than conventional mechanical coupling methods. However, in addition to forming the connection

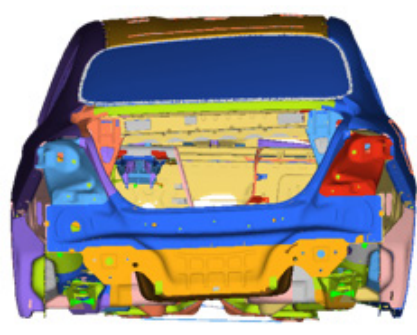

Torsional Mode

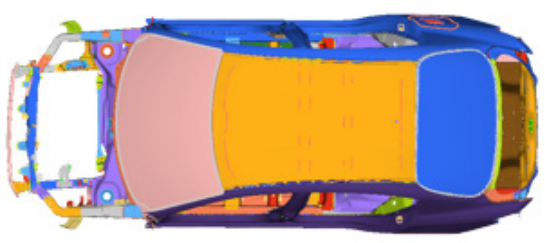

Lateral Bending Mode

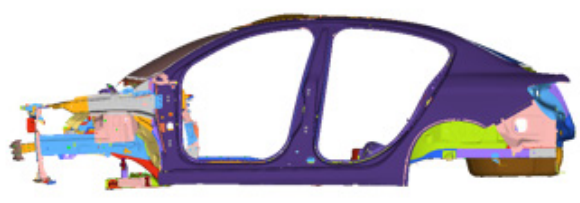

Vertical Bending Mode

Figure 8. NVH analysis in BIW model

\section{Torsional Stiffness}

The torsional stiffness of the vehicle has been made with the composite SWW, and there is no decrease compared to the present situation. (Fig 9)

\section{Rear Crash}

This component must pass a number of tests. Spare-wheel wells mounted into the vehicle must meet impact require- at a lower cost and weight, the adhesives may provide equivalent or greater bond strength to the mechanical joining methods. In addition, design flexibility, improved stiffness of the joint, ability to noise and vibrations are the other main advantages of the adhesive joining.[12]

Instead of being riveted to the BIW, composite wheel wells are elastomerically bonded, generally with the same urethane adhesive system used to bond glass windshields to the 
frame. To ensure the part stays flat and cures properly against the steel frame, a 10-kg weight is set inside the well for approximately 30 min during assembly. It is removed when the spare tire is placed inside the well. [5]

With a structural paste to be applied around the composite part; both the incoming force has been met across the entire adhesion surface and we have eliminated the water infiltration problem. The composite part and the seating surfaces that are in contact must be designed to allow for paste application. The application cross-section can be seen in Figure 11.

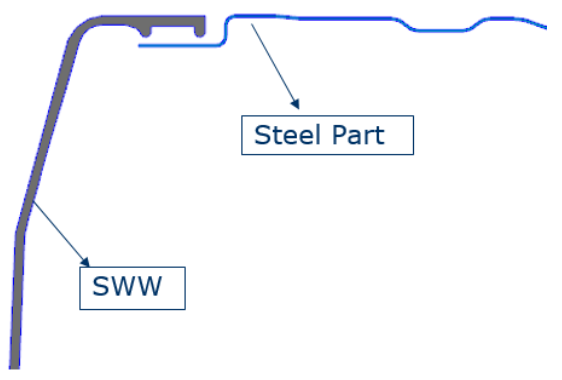

Figure 11. Composite Part Adhesive application section

\section{CONCLUSION}

Although steel material is still the most common material used on vehicle body, automotive manufacturers have gone to reduce vehicle weight by using alternative materials to reduce $\mathrm{CO}_{2}$ emissions. Easy recycling and short shaping cycling GMT as a successful alternative to such material with high mechanical and chemical properties.

In this study, GMT-GMTex material has been used for the SWW design to reach $2 \mathrm{~kg}$ (from 12,2 $\mathrm{kg}$ to $10,15 \mathrm{~kg}$ ) weight reduction per vehicle and at the same time no loss of vehicle performance.

In our study design studies were carried out for spare wheel well, the resulting designs were examined by numerical analysis methods and weak points were improved with the necessary design activities. As a result of the improvements made according to the numerical analysis reports, the expected results were obtained. It was observed that the forms on the part design had a high effect on Modal Analysis and Torsional Stiffness and the rate of GMT-GMTex material affected Rear crash performance.

With the use of spare wheel well in passenger vehicles, it has been observed that the NVH quality of the vehicle improves positively the customer's perceive quality. It has been found that an improved design supported by numerical analyzes can meet the same function requirements as sheet metal architecture.

\section{ACKNOWLEDGEMENTS}

The authors acknowledge the Scientific and Technological Research Council of Turkey (TÜBİTAK) for the financial support under the Project TEYDEB 3160497. TOFAŞ-FIAT Automotive Factory, Bursa, Turkey is acknowledged for sup- porting this research.

\section{NOMENCLATURE}

GMT Glass-Mat Reinforced Thermoplastic

GMTex Fabric Reinforced Thermoplastic

BIW Body in White

SWW Spare-wheel well

\section{REFERENCES}

[1] Zhao Liu, Jiahai Lu, Ping Zhu, 2016. Lightweight design of automotive composite bumper system using modified particle swarm optimizer, Available online 4 January

[2] Yuxuan Li *, Zhongqin Lin, Aiqin Jiang and Guanlong Chen, 2004. Experimental study of glass-fiber mat thermoplastic material impact properties and lightweight automobile body analysis, Automobile Body Manufacturing Technology Center, Shanghai Jiao Tong University, Shanghai 200030, PR China

[3] http://www.quadrantplastics.com

[4] Do-Hyoung Kim a, Hyun-Gyung Kim b, Hak-Sung Kim, 2015. Design optimization and manufacture of hybrid glass/carbon fiber reinforced composite bumper beam for automobile vehicle, Available online 19 June 2015

[5] Marcia Kurcz, M., Baser, B., Dittmar, H., Sengbusch, J., Pfister, H., Quadrant Plastic Composites, AG

[6] (http://www.compositesworld.com/articles/spare-wheel-well-functional-integration)

[7] G. Belingardi, A.T. Beyene, Dang Jichuan, 2016. Energy absorbing capability of GMT, GMTex and GMT-UD composite panels for static and dynamic loading - Experimental and numerical, Available online 12 February 2016

[8] https://www.a2mac1.com/Autoreverse/

[9] (http://slideplayer.com/slide/2494611/)

[10] (http://www.plasticomp.com/long-fiber-benefits/)

[11] Aksel, L., Efendioğlu, Ş., Yeni, H., Bilge, Ç. 2016. Weight Reduction Study on BIW by Using Boron Alloyed Hot Stamping Solution of Front Frame Rail Instead Conventional HSS or AHSS Applications, International Conference on Advanced Technology \& Sciences (ICAT'16)

[12] Belingardi, C., PhD, Professor, Martorana, B., 2014. Recent Research Results in Composite Materials and Adhesive Applications For vehicle Lightweight, Volume 40, Number 2, 2014

[13] https://www.mcam.com/asia-en/products/composite-material/ gmtexc2/

[14] Quadrant Plastic Catalog 